\title{
Water Purification by a Micelle-Clay Composite Alone and its Collaboration with other Technologies
}

\section{Shlomo Nir*}

Department of Soil and Water Sciences, Hebrew University of Jerusalem, Israel

${ }^{*}$ Corresponding author: Shlomo Nir, Department of Soil and Water Sciences, The Robert H. Smith Faculty of Agriculture, Food and Environment, The Hebrew University of Jerusalem, Rehovot, 76000, Israel, Tel: +972-8949172; Fax: +972-

\begin{tabular}{|c|}
\hline Mini Review \\
Volume 2 Issue 1 \\
Received Date: February 11, 2019 \\
Published Date: March 05, 2019 \\
DoI: $10.23880 /$ oajwx-16000118 \\
\hline
\end{tabular}
89475181; Email: shlomo.nir@mail.huji.ac.il

\section{Abstract}

Removal of chemicals and pathogenic microorganisms by filtration may provide safe drinking water, and decrease the risk from harmful disinfection by products. Micelle-clay complexes produced have a relatively large surface area, large hydrophobic fractions, and are positively charged to about half of the cation exchange capacity of the clay. Their material characteristics differ from those of organo-clays of the same composition, which are formed by adsorption of cations as monomers. Granulated micelle-clay composites $(0.4$ to $2 \mathrm{~mm})$ formed by the organic cation ODTMA (Octadecyltrimethylammonium), removed efficiently from water by filtration chemicals, such as herbicides, and dissolved organic matter, pharmaceuticals, perchlorate, and microorganisms, such as bacteria, viruses and a parasite, such as crytosporidium. Bacteria removed included (a) Escherichia coli S-17; (b) total bacteria count (TBC); and (c) Cyanobacteria (Microcystis and Aphanizomenon). A model which considered convection, adsorption, and desorption simulated the filtration results and yielded predictions. The emphasis in this minireview is on collaboration of this technology with other procedures, which may enhance treated water quality and reduce the costs of treatment. Thus a new approach intends to utilize both filtration and biocidal/biostatic activity of free cations in removal of microorganisms from water. A two stage purification of greywater by a moving bed reactor followed by a micelle-clay filter yielded an order of magnitude increase in the capacity of the filter. Water purification by filtration followed by solar photocatalysis enabled removal of recalcitrant molecules and indicator bacteria from secondary treated wastewater, thus yielding high quality water for irrigation. Other examples are reduction of membrane fouling of UF membranes and a suggested reduction of fouling of RO membranes by a pretreatment by the micelle-clay filter, or its combination with granulated activated carbon filter.

Keywords: Nano-Composite; Granulated Micelle-Clay; Filtration Modeling; Removal of Bacteria; Biocidal Effects; Greywater Reuse; Combined Filtration and Photocatalysis 


\section{Introduction}

Quite a few sources provide drinking water without a need for treatment, which involves removal of chemicals and pathogenic microorganisms. In the simplest cases the authorities of health regulate the addition of disinfectants, which have been shown to cause health problems due to by products, which have to be monitored, and in certain cases have to be partially removed [1]. With the appearance of harmful residues of pharmaceuticals and pesticides, it has become clear that one method, or procedure is rarely sufficient, and a collaboration of procedures is clearly essential, both in terms of water quality, and costs [2]. In this mini review we present a few examples of collaborations involving the micelle-clay complex, which has been shown to be powerful in removal of microorganisms and chemicals, but recalcitrant molecules have been encountered. This problem is mainly critical in treatment of wastewater.

\section{Production and Characteristics of the Micelle- Clay Complex}

A dissolution of a salt of ODTMA (Octadecyltrimetyhylammonium)- $\mathrm{Br}$ in water at concentrations of several $\mathrm{mM}$, and elevated temperatures of $50-60^{\circ} \mathrm{C}$ results in formation of micelles. The critical micelle concentration (CMC) of the organic cation ODTMA is $0.3 \mathrm{mM}$. Hence, at ODTMA concentrations of 10 to $30 \mathrm{~g}$ per liter, most of the cation is in micellar form, in which the positive charge of the cation is located on the external surface of the micelle, and the internal surface, which is devoid of water, includes the alkyl chains between which van der Waals interactions exist. The micelle-clay complexes produced by adding clay, such as Na-bentonite have a relatively large surface area; they include large hydrophobic fractions and are positively charged to about half of the cation exchange capacity (CEC) of the clay. The material characteristics of the micelle-clay complex differed from those of a tested organo-clay complexes of the same composition, which were formed by adding ODTMA as monomers [3].

\section{Laboratory and Pilot Experiments have Yielded Efficient Removal from water of}

- Hydrophobic and anionic organic molecules, such as herbicides; humic acid, dissolved organic matter; pharmaceuticals [2-13].

- Inorganic anions, e.g., perchlorate, ferricyanide (Nir, unpublished) [14].

- Microorganisms, whose external surfaces are net negatively charged. Such as bacteria, viruses, and parasites, e.g., cryptosporidium, which is resistant to chlorination? Low cost regeneration of used filters after bacteria adsorption is described in Shtarker-Sasi, et al., Rakovitsky, et al. and Kalfa, et al. [15-17]. The experimental results coupled with model calculations have indicated that the micelle-clay filter is very economical in removal of microorganisms from water by filtration. However, we will present cases where the economy and quality of water purfication by the micelle- clay filter purification are enhanced significantly by other elements and technologies. Vice versa, the micelle-clay technology can provide a polish to water purification by other technologies. Briefly, we advocate collaboration between technologies.

\section{Biocidal Effects of Quaternary Amine Cations (QACs)}

Biocidal and biostatic effects of cations, (mainly QACs) have been widely reported [18-21]. Sukenik, et al. demonstrated that addition of $75 \mu \mathrm{g} / \mathrm{L}$ ODTMA cations abolished completely the photosynthetic activity of Aphanizomenon (cyanobacteria) cells within 20 to $40 \mathrm{~min}$. Kalfa, et al. suggested that a micelle-clay complex which released during filtration a larger number of QACs was more efficient in removing from water bacteria, due to the biocidal/biostatic effect of the released cations $[17,22]$. This might suggest that removal of bacteria from water by filtration is expected to be more efficient by a small increase of the ratio of ODTMA/ clay in the complex, which will enhance the concentrations of cations released during filtration. Preliminary results of Margalit and Nir (unpublished) gave support to this suggestion by filtration of tap water which included total count bacteria.

The released cations are removed from water before consumer use by another filter containing activated carbon. Drinking water from lakes is forbidden during cyanobacteria bloom, due to harmful toxins. Filtration by the granulated micelle-clay complex and killing of cyanobacteria by ODTMA cations are described in Sukenik, et al. [22] .

\section{A Two Stage Purification of Greywater by a Moving Bed Reactor Followed by a Filter}

Reuse of grey water (GW) enables to save significant amounts of fresh water. Grey water from sinks outside the kitchen, showers and baths amounts daily to 150-300 L per household. Use of inadequately treated GW can be a potential health hazard [23]. A moving bed reactor (MBR) was used by Winward, et al. [24]. Bani-Melhem and Smith used a submerged MBR for removal of anionic surfactants and coliforms [25]. Friedler, et al. combined biological treatment using a rotating biological contactor (RBC) with a sedimentation stage, a sand filtration stage and a 
hypochlorite disinfection stage [26]. RBCs combined with sand filtration and UF membranes and combined with UV disinfection were tested for treatment of GW. Constructed wetlands have been employed for GW treatment. Gross, et al. and Benami, et al. employed a recirculating vertical flow constructed wetland (RVFCW), whereas Travis, et al. examined the use of an anaerobic pretreatment stage before treatment of GW by RVFCW [24,27-33, 35]. Santos, et al. tested purification of GW by a hydraulically, selfcleaning mesh filter followed by UV disinfection. Thus it follows that in the area of grey water treatment, collaboration of technologies has been considered about a decade ago [33]. Brook, et al. indicated that an activated carbon filter yielded poor removal of bacteria even after the passage of $5 \mathrm{~L}$ [34]. A comparison of these results with those of several recent studies which employed a variety of technologies for treatment of greywater demonstrated the advantage of the micelle-clay complex in reducing significantly the number of pathogenic bacteria, despite the relatively small amounts of the complex.

The biological reactors, which were introduced with the aim of reducing the amount of organic material in the grey water, also significantly reduced the number of fecal coliforms $[16,36]$. The two-stage purification procedure, i.e., preincubation of $\mathrm{GW}$ in a bioreactor followed by filtration, increases the purification capacity of the filter filled with the complex by an order of magnitude. The bioreactor was effective in reducing the concentration of the organic material and the numbers of fecal coliforms in the GW. Regeneration of the micelle-clay granules could be accomplished by $\mathrm{NaOCl}(0.5 \%)$, or $\mathrm{HCl}(0.05 \mathrm{mM})$, or by heating at $120^{\circ} \mathrm{C}$ for $3 \mathrm{~h}$. The capacity of the granulated complex to purify grey water from showers baths and sinks amounts to $20 \mathrm{~m}^{3}$ per $\mathrm{kg}$ of the granulated complex, and when two regenerations are considered the capacity becomes $47 \mathrm{~m}^{3}$ per $\mathrm{kg}$ of the complex. The two - stage procedure yields a safe and economical reuse of GW, since the plan is to have $<1$ per $100 \mathrm{~mL}$ of fecal coliforms or other indicator, or pathogenic bacteria in the filtered water.

In passing, it might be of interest to test a collaboration of Constructed Wetlands with filtration by the granulated micelle-clay complex, or with the twostage treatment by a moving bed reactor followed by a filter.

\section{Water purification by Filtration Followed by Degradation}

A few molecules denoted recalcitrant are not removed efficiently from water by filtration, e.g., carbamazepine. It turns out that such molecules as well as others can be removed from secondary treated wastewater by photo degradation. The efficiency of removal of such molecules by photo degradation from pools of treated wastewater is small, due to the presence of other molecules and loss of intensity of radiation, which penetrates into deeper depths. The combination of filtration and degradation can on one hand enable to remove recalcitrant pollutants from water, and on the other hand purify the water from several other pollutants and enhance the efficiency of removal of many pollutants by degradation.

In a recent pilot experiment a tertiary treatment of effluent from a secondary treated wastewater was tested by combining filtration and solar photocatalysis [37, 38]. The water to be purified included $26.3 \mathrm{mg}$ of TOC. Such a load of organic materials might reduce significantly the capacity of the micelle-clay filter to capture the ECs in the water and the bacteria: $10^{5}$ and $10^{4}$ of Escherichia Coli and Enterococcus faecalis per $\mathrm{mL}$, respectively. The filtration system included a first filter $(2 \mathrm{~cm} \cdot 50 \mathrm{~cm})$ with $70 \mathrm{~g}$ of GAC, followed by a second filter $(2 \mathrm{~cm} \cdot 40 \mathrm{~cm})$ which included $20 \mathrm{~g}$ of granulated micelle (ODTMA)montmorillonite mixed with $100 \mathrm{~g}$ of sand (grain size of 0.8-1.5 mm). Wastewater effluent (45 L) was pumped at a flow rate of $10 \mathrm{~mL} / \mathrm{min}$. Thirteen ECs were selected as representatives of the most common micropollutants in wastewater: Ketoprofen, caffeine, carbamazepine, sulfamethoxazole, atenolol, amoxicillin, venlafaxine, tamoxifen, sulfamethazine, fenofibric acid, mepanypirim, chlotianidin and diclofenac.

The applied solar advanced oxidation process was homogeneous photo-Fenton photocatalysis using peroxymonosulfate (PMS) as oxidant agent. This combination of technologies aimed to ensure water disinfection and removal of emerging contaminants (ECs, mainly pharmaceuticals). The filtration step showed good performance in removing dissolved organic matter mostly by the GAC filter and also by the micelle-clay filter. On the other hand a practically complete removal of the bacteria, from the secondary treated water was achieved by the micelle-clay filter, whereas the GAC filter had low efficiency of bacterial removal. Solar advanced oxidation processes were efficient in elimination of trace levels of ECs. The final effluent presented an improved sanitary level with acceptable chemical and biological characteristics for irrigation.

\section{Additional Possible Collaborations of Technologies}

The WWTP in the Campus of the University Al-Quds includes a sequence of treatment elements, 2 UF membranes, a GAC filter and a RO membrane. It was 


\section{Open Access Journal of Waste Management \& Xenobiotics}

suggested in several publications, e.g., Karaman, et al. that it would be beneficial to add a filter based on granulated micelle-clay complex before the UF element denoted SW ( $20 \mathrm{kD}$ cut off) and another one before the RO, in order to reduce membrane fouling in these two elements, thus save on the needed energy The rationale was that the micelle-clay filter is efficient in removal of bacteria, which are a main cause of membrane fouling by sorption and a formation of a biofilm [2]. The study of Brienza, et al. also demonstrated that a GAC filter placed before the micelleclay filter removed a great deal of the dissolved organic material, thus making the micelle- clay filter more efficient in removing bacteria from the water entering the RO membrane [37].

\section{Conclusions}

This articles advocates collaboration between technologies for enhancing the quality of treated water and the economy of the process. Examples for the usefulness of such collaboration are presented in several cases. 1. Filtration by the granulated micelle-clay complex, where a consideration of biostatic and biocidal effects of QACs may enhance dramatically the capacity of purification of water from microorganisms. The residues of QACs can be removed by activated carbon. 2. Water purification by filtration by means of (i) activated carbon followed by a micelle-clay and (ii) photodegradation. This process is promising for removal of recalcitrant molecules, TOC and microorganisms at a low cost.

\section{References}

1. Bond T, Huang J, Templeton MR, Graham N (2011) Occurrence and control of nitrogenous disinfection by-products in drinking water-A review. Water Res 45(15): 4341-4354.

2. Karaman R, Khamis M, Abbadi J, Amro A, Qurie M, et al. (2016) Paracetamol biodegradation by activated sludge and photo-catalysis and its removal by a micelle-clay complex, activated charcoal and reverse osmosis membranes. Environ Technol 37(19): 24142427.

3. Mishael YG, Undabeytia T, Rytwo G, PapahadjopoulosSternberg B, Rubin B, et al. (2002) Sulfometuron adsorption via alkylammonium cations adsorption as monomers and micelles on montmorillonite. J Agric Food Chem 50: 2856-2863.

4. Mishael YG, Undabeytia T, Rabinovitz O, Rubin B, Nir $S$ (2003) Sulfosulfuron incorporated in micelles adsorbed on montmorillonite for slow release formulations. J Agric Food Chem 51(8): 2253-2259.

5. Polubesova T, Nir S, Rabinovitz O, Borisover M, Rubin B (2003) Sulfentrazone Adsorbed on MicelleMontmorillonite Complexes for Slow Release in Soil. J Agric Food Chem 51(11): 3410-3414.

6. Nir S, Zadaka-Amir D, Kartaginer A, Gonen Y (2012) Simulation of adsorption and flow of pollutants in a column filter: Application to micelle-clay mixtures with sand. Applied Clay Sci 67-68: 134-140.

7. Radian A, Carmeli M, Zadaka-Amir D, Nir S, Wakshal E, et al. (2011) Enhanced Removal of Humic Acid from Water by Micelle-Montmorillonite Composites: Comparison to Granulated Activated Carbon. Appl Clay Sci 54(3-4): 258-263.

8. Polubesova T, Zadaka D, Groisman L, Nir S (2006) Water remediation by micelle-clay system: case study for antibiotics. Water Res 40(12): 2369-2374.

9. Karaman $\mathrm{R}$, Khamis $\mathrm{M}$, Qurie $\mathrm{M}$, Halabieh $\mathrm{R}$, Makharzeh I, et al. (2012) Removal of Diclofenac Potassium from Wastewater Using Clay-Micelle Complex. Environ Technol 33(10-12): 1279-1287.

10. Khalaf S, Karaman R, Al-Rimawi F, Khamis M, Zimmerman D, et al. (2013) Efficiency of membrane technology, activated charcoal, and a clay micelle complex for removal of the acidic pharmaceutical ibuprofen. J Environ Sci Health Part A 48(13): 1-8.

11. Qurie M, Khamis M, Malek F, Nir S, Scrano L, et al. (2013) Efficiency of advanced membrane wastewater treatment plant and micelle-clay complex towards removal of Naproxen. Clean Soil, Air and Water Journal 42(5): 594-600.

12. Sulaiman S, Khamis M, Nir S, Lelario F, Scrano L, et al. (2015) Stability and Removal of Atorvastatin, Rosuvastatin and Simvastatin from Wastewater. Env Technol 36(24): 3232-3242.

13. Awwad M, Al-Rimawi F, Jamal K, Dajani K, Khamis M, et al. (2015) Removal of Amoxicillin and Cefuroxime Axetil by Advanced Membranes Technology, Activated Carbon and Micelle-Clay Complex. Env Technol 36(13-16): 2069-2078.

14. Nir S, Brook I, Anavi Y, Ryskin M, Ben-Ari J, et al. (2015) Water purification from perchlorate by a micelle-clay complex: Laboratory and pilot experiments. Appl Clay Sci 114: 151-156. 


\section{Open Access Journal of Waste Management \& Xenobiotics}

15. Shtarker-Sasi A, Castro Sowinski A, Matan O, Kagan T, Nir S, et al. (2013) Removal of bacteria and Cryptosporidium from water by micellemontmorillonite complexes. Desalination Water Treat 51(40-42): 7672-7680.

16. Rakovitsky N, Brook I, Van Rijn J, Ryskin M, Mkhweli $\mathrm{Z}$, et al. (2016) Purification of greywater by a moving bed reactor followed by a filter including a granulated micelle-clay composite. Appl Clay Sci 132-133: $267-$ 272.

17. Kalfa A, Rakovitsky N, Tavassi M, Ryskin M, Ben-Ari J, et al. (2017) Removal of E. coli and total bacteria from water by granulated micelle- clay complexes: Filter regeneration and Modeling of filtration kinetics. Appl Clay Sci 147: 63-68.

18. Thorsteinsson $T$, Masson $M$, Kristinsson $K G$, Hjalmarsdottir MA, Hilmarsson $\mathrm{H}$, et al. (2003) Soft antibacterial agents: synthesis and activity of labile environmentally friendly long chain quaternary ammonium compounds. J Med Chem 46(19): 41734181.

19. Gilbert P, Moore LE (2005) A review Cationic Antiseptics: Diversity of Action Under a Common Epithet. J Appl Microbiol 99(4): 703-715.

20. Ferreira C, Pereira AM, Pereira MC, Melo LF, Simoes M (2011) Physiological changes induced by the quaternary ammonium compound benzyldimethyldodecylammonium chloride on Pseudomonas fluorescens. J Antimicrob Chemother 66(5): 1036-1043.

21. Inacio AS, Domingues NS, Nunes A, Martins PT, Moreno MJ, et al. (2016) Quaternary ammonium surfactant structure determines selective toxicity towards bacteria: mechanisms of action and clinical implications in antibacterial prophylaxis. J Antimicrob Chemother 71(3): 641-654.

22. Sukenik A, Viner-Mozzin Y, Tavassi M, Nir S (2017) Removal of cyanobacteria and cyanotoxins from lake water by composites of bentonite with micelles of the cation octadecyltrimethyl ammonium (ODTMA). Water Res 120: 165-173.

23. Gross A, Maimon A, Alfiya Y, Friedler E (2015) Greywater Reuse. CRC Press. Taylor \& Francis, pp: 306.

24. Winward GP, Avery LM, Frazer-Williams R, Pidou M, Jeffrey P, et al. (2008) A study, 187-197.
25. Bani-Melhem K, Smith E (2012) Greywater treatment by a continuous process of an electrocoagulation unit and a submerged membrane bioreactor system. Chem Eng J 198-199: 201-210.

26. Friedler E, Kovalio R, Galil NI (2005) On-site greywater treatment and reuse in multi-storey buildings. Wat Sci Tech 51: 187-194.

27. Friedler E, Kovalio R, Ben-Zvi A (2006) Comparative study of the microbial quality of greywater treated by three on-site treatment systems. Environ Tech 27(6): 653-663.

28. Gilboa Y, Friedler E (2008) UV disinfection of RBCtreated light greywater effluent: kinetics, survival and regrowth of selected microorganisms. Water Res 42(4-5): 1043-1050.

29. Vymazal J (2007) Removal of nutrients in various types of constructed wetlands. Sci Total Environ 380(1-3): 48-65.

30. Gross A, Shmueli O, Ronen Z, Raveh E (2007) Recycled vertical flow constructed wetland (RVFCW)a novel method of recycling greywater for irrigation in small communities and households. Chemosphere 66(5): 916-923.

31. Benami M, Gross A, Herzberg M, Orlofsky E, Vonshak A, et al. (2013) Assessment of pathogenic bacteria in treated graywater and irrigated soils. Sci Total Environ 458-460: 298-302.

32. Travis M, Weisbrod N, Gross A (2012) Decentralized wetland-based treatment of oil-rich farm wastewater for reuse in an arid environment. Ecol Eng 39: 81-89.

33. Santos C, Teveira-Pinto F, Cheng CY, Leite D (2012) Development of an experimental system for greywater reuse. Desalination 285: 301-305.

34. Brook I, Malchi T, Nir S (2015) Removal of anionic detergents from water and treatment of greywater by micelle-clay composites. Desalination and Water Treatment 53(8): 2184-2192.

35. Travis MJ, Wiel-Shafran A, Weisbrod N, Adar E, Gross A (2010) Greywater reuse for irrigation: Effect on soil properties. Sci Total Environ 408(12): 2501-2508.

36. Odegaard $H$ (2006) Innovations in wastewater treatment: the moving bed biofilm process. Water Sci Technol 53(9): 17-33. 
37. Brienza M, Nir S, Plantard G, Goetz V, Chiron S (2018) Combining micelle-clay sorption to solar photofenton processes for domestic wastewater treatment. Environ Sci and Pollut Res.
38. (WHO) World Health Organization (2006) Overview of greywater management, health considerations. Regional Office for the Eastern Mediterranean Centre for Environmental Health Activities. Amman, Jordan, pp: 1-49. 